\title{
The Importance of Aberrant DNA Methylation in Cancer
}

\author{
Koraljka Gall Trošelj, Renata Novak Kujundžić \\ and Ivana Grbeša \\ Rudjer Boskovic Institute, \\ Division of Molecular Medicine, Zagreb, \\ Croatia
}

\section{Introduction}

Cancer has long been considered primarily a genetic disease, caused by different mutations throughout the genome. In 1983., Feinberg and Vogelstein discovered that the level of DNA methylation significantly varies between primary human malignant tumors and their normal counterparts (Feinberg \& Vogelstein, 1983). Before this publication, there had been a paper describing changes in DNA methylation in cancer cell cultures, including the influence of N-methyl-N-nitrosourea on the level of DNA methylation in Raji cells (Boehm \& Drahovsky, 1981). Currently, we are presented with much experimental data showing multilevel changes in cancer cells. In this context, two major areas of epigenomic research DNA methylation and histone modifications appear most promising in understanding the multistep nature of carcinogenesis. Additionally, they seem to have the potential for being cancer biomarkers, useful in early detection, in predicting the biological behavior of tumors and for therapy monitoring, as recently reviewed (Rodriguez-Paredes \& Esteller, 2011; Baylin \& Jones, 2011). Finally, epigenetic changes are well-recognized targets for cancer therapy, alone, or in combination with various cytostatics (Ren et al, 2011). Epigenetic changes are also of the greatest importance in chemoprevention, as there is increasing data relating to possibly reversing epigenetic changes in the earliest phase of carcinogenesis, when genetic changes have yet to develop (reviewed, Huang et al., 2011). It is not easy to understand the particular rules applicable to epigenomic processes. If one specific epigenetic change, relating to a specific gene/its promoter, exists in a majority of tumors of a specific type, it does not necessarily mean that the same change exists in another type of tumor. This is consequential, and represents one reason for obvious differences in responses to epigenomic therapy. Recently, we wrote a review article on some aspects of epigenomic changes in which we used the term "epigenetic networking“. If we imagine each of our living cells as an orchestra performing the symphony of life, then each player (a gene) of the orchestra needs to play in concert with 30,000 other players. The communication that produces the network of our epi-genome is established at many levels: transcriptionally, post-transcriptionally, through protein translation, at the level of post-translational protein modifications, through their orchestrated interactions and, finally, their interaction with the DNA that can be modified in order to accept or reject the protein partner. This is the way of 
controlling gene activity and why we, in the previously mentioned review paper, considered epigenomic changes as "A Bird's Eye Perspective on the Genome“ (Gall Trošelj \& Novak-Kujundžić, 2010).

\section{Cancer, DNA methylation and factors beyond our control}

A disturbed DNA methylation pattern represents, most probably, the best and most commonly studied epi-change. This change has been extensively documented, especially after the introduction of genome-wide analytical methods which clearly confirmed, on a very broad scale, that both gain and loss in DNA methylation are very frequent events in cancer (reviewed, Ndlovu et al., 2011). It has been known for some time that de novo DNA methylation of promoter CpG island (CpGI) does not occur accidentally (Choi et al., 2010). An arbitrary border at $-1 \mathrm{kB}$ upstream and $+0.5 \mathrm{~kb}$ downstream from the transcription start site shows that some $60 \%$ of human genes associate with CpG islands.

Until 2007, the definition of the CpG island was primarily related to the primary structure of DNA molecule. In 1987, Gardiner-Garden and Frommer established the generaly accepted definition (200 bp long stretch of DNA with a GC content $>50 \%$ and an observed $\mathrm{CpG}$ /expected $\mathrm{CpG} \geq 0.6$ ) that, as realized later, did not make a stringent distinction between bona fide CpG islands and Alu repates (Gardiner-Garden \& Frommer, 1987). In 2002, this obstacle was properly addressed and a new definition of the CpG island, commonly used in the field of cancer research, was offered: It is the DNA region longer than $500 \mathrm{bp}$, with a GC content $\geq 55 \%$ and observed CpG/expected CpG of 0.65 . (Takai \& Jones, 2002). The percentage number for defining "the promoter rich in $\mathrm{CpG}^{\prime \prime}$ varies; the most commonly used number is usually 55\% (Espada \& Esteller, 2007). However, it became obvious that these definitions lack a clear biological justification and do need improvement as they, although sufficiently sensitive in detecting majority of bona fide CpG islands in the humane genome, lack of specificity leading to a considerably high number of false positive results. In 2007, the computational modeling was used to estimate the "CpG Island Strength", based on predicted epigenetic state and chromatine structure, on non-repetitive parts of chromosomes 21 and 22. The "combined epigenetic score" that was based on available "open and transcriptionally competent chromatine structure" epigenomic data (including H3K4 di- and trimethylation, H3K9/14 acetylation, DNAse I hypersensitivity and Sp1 transcription factor binding), allowed for meaningful interpretation. Between the scores of " 0 " and " 1 " that related to a particular CpGI function (where " 0 " represented silenced, inactive and inaccessible island, and " 1 " represented unmethylated, highly accessible CpGI with prominent promoter activity), the value of 0.5 turned out to be equally likely to correspond to both, bona fide CpGI and the region of DNA that is not a CpGI. Hence, the 0.5 value was recommended as a threshold for majority (although not all) future applications. This approach has profiled 21,631 CpG islands on the tested chromosomes and, for high specificity mapping of CpGI, the map of predicted CpGIs based on the combined epigenetic score was suggested (Bock et al., 2007).

The CpG islands are rarely methylated in normal tissue (except for X-chromosome inactivated and imprinted genes). However, in cancer, the picture changes dramatically. Aging also represents a process relating to a linear increase of the level of DNA methylation in CpG rich gene promoters. On the other hand, paradoxically, the global level of methylation in older cells/tissues seems to be decreased. This clearly mimics the 
methylation status of a cancer cell. However, one should be critical when trying to understand what really happens in the living cell: very similar cell types derive from different stem cell niches and their epigenomes may differ significantly (Kim at al., 2005). In addition, as recently discussed (Ehrlich, 2009), the major problem in quantitative DNA methylation studies dealing with native clinical samples is the presence of cells that are nonneoplastic. When dealing with a tumor tissue that was taken in a surgical theater and immersed in liquid nitrogen immediately after extirpation, one can be more than convinced that non-tumorous cells are present in a sample. The percentage of "contaminating", nontumorous cells varies from sample to sample. Even if we deal with very similar, relatively "clean", native tumors, we must be aware that every cell divides with its own dynamics. Hence, not all cells are in the same phase of the cell cycle. So, the whole cellular content of the tumor represents, in a percentage that varies, a mixture of very heterogeneous, cell-cycle related, methylomes. Accordingly, what we measure when using the methods that are not in situ, is a mixture of signals and we (usually) focus on the most prominent ones. But it does not mean that the signals that are less prominent are less important for the tumor in toto.

The problem becomes even more prominent in comparative analyses, when tumor tissue needs to be compared to non-tumorous, adjacent tissue. Our group was not the only one that has shown, unexpectedly, the change in imprinting status of IGF2 in a tissue adjacent to laryngeal cancer (Grbeša et al., 2008). It seemed "normal“ to the surgeon, and, back then in 2005, the simplest thought was that we mixed up tumorous and non-tumorous samples. Even at that time, we were quite careful with tumor samples, as years of experience taught us to take only a small portion of tissue for analyses, leaving at least one small piece of tissue in our tumor bank (Spaventi et al. 1994). After obtaining confusing results, this residual piece of tissue was given to a very experienced pathologist who needed to answer our question: "Is this the tumor"? Morphologically, it was not the tumor. Epigenetically, it showed loss of IGF2 imprinting. Based on that finding - it did not appear as "normal tissue". We still think that, especially in smoking-related cancer, this specific change may be the first sign of "abnormality".

In addition to obvious problems relating to exploring the DNA methylation status in native tumors, there are also very specific problems when using cell cultures. As shown by Asada, who used several different rat liver cell lines (including a primary cell line), methylation level increases significantly after 10 passages. Hence, the authors concluded that, at least in their experimental model, , a cautious approach is required when cell lines are utilized to study methylation-related carcinogenesis, metastatic or tumoricidal mechanisms" (Asada et al., 2006).

Based on this brief but, hopefully, informative data relating to objective limitations of the system based on factors beyond our control, we enter the field of cancer epigenomics.

\section{Cancer and DNA methyltransferases}

DNA methyltransferases (DNMTs) are the only enzymes which have been shown to mediate the transfer of a methyl group from S-adenosylmethionine (SAM) to the C-5 position of cytosine, mainly in CpG nucleotides, in mammalian genomes. Although detected, cytosine methylation is very rare in the outside of $\mathrm{CpG}$ sequences, at least in differentiated cells. For example, $99.98 \%$ of all methylation in mature fibroblasts occur at CpG dimers. This number is significantly reduced in both embryonic and induced stem cells (Lister et al., 2009). 
In mammals, there are four DNMTs: DNMT1, DNMT2, DNMT3A, DNMT3B. While DNMT1 has the highest importance in maintaining post-replicative DNA methylation patterns, DNMT3A and $-3 \mathrm{~B}$ are considered critical players in establishing de novo methylation patterns. They also assume maintenance activity. DNMT3L, discovered in 2000 (Aapola et al., 2000), is a regulatory factor for de novo methylation. Its amino acid sequence is very similar to that of DNMT3a and DNMT3b but lacks the residues required for DNA methyltransferase activity in the C-terminal domain.

It was shown that the fidelity in replicating methylation patterns in human non-cancerous, dividing cells reaches $99.85-99.92 \%$ per site, per generation in CGs reach promoters and 99.56-99.83\% in CGs outside the promoters (Ushijima et al., 2003). Human cancer gastric cell lines showed decreased fidelity in maintaining the methylation pattern which manifested through an increased level of de novo DNA methylation in promoter regions of five tested cancer-related genes and 4- to 8-fold higher expression of de novo DNMT3B. This increase was highest in two cell lines that showed the highest level of decreased fidelity (Ushijama et al., 2005). The question remains: was the increased level of DNMT3B alone sufficient to induce so prominent change at the promoters of these genes?

\subsection{DNA Methyltransferase 1 (DNMT1)}

Homozygous knockout of DNMT1 is lethal to the embryo in mammals. On the other hand, studies on DNMT1-overexpression in embryonic stem cells also resulted in lethality of the embryo, suggesting that accurate expression of DNMT1 is a key factor in maintaining embryonic development (Biniszkiewicz et al., 2002).

For maintaining the methylation pattern during cell division, the cellular machinery uses DNMT1. After replication, 5-mC is present only on one parental DNA strand and the methylation of cytosines on the newly synthesized strand takes place on the cytosine that lies diagonally opposite to 5-mC in the parent DNA strand. Keeping the methylation pattern as inheritable modification that needed to be preserved during cell division was originally published in 1975 by three independent researchers/research groups (Holliday \& Pugh 1975; Riggs, 1975). Since then, our knowledge has been significantly advancing, especially as a result of fast developing molecular techniques. However, it does not matter how rapidly our research progresses, the importance of the discovery published in 1975 remains astonishing, even from the most sophisticated molecular perspective.

During the S-phase of the cell cycle, DNMT1 was found to be localized to DNA replication foci through its interaction with proliferating cell nuclear antigen (PCNA). The precise cellcycle-dependent localization of DNMT1 depends on the protein UHRF1, also known as ICBP and NP95. This protein shows strong preferential binding to hemimethylated CG sites through its methyl DNA binding domain, and tethers DNMT1 to replication fork (Bostick et al., 2007; Sharif at al., 2007). The DNMT1 also interacts with histone deacetylases resulting in repressing gene expression or forming heterochromatin structure.

\subsubsection{DNMT1 and post-translational modifications}

Little is known about post-translational modification of DNMT1, that may, possibly, change its functioning, especially in cancer. There are several in vitro studies pointing out the 
protein kinases involved in DNMT1 phosphorylation. From the perspective of cancer research, the AKT and PKC certainly are very promising candidates that may help us to better understand the functioning of DNMT1. Both kinases were shown to phosphorylate recombinant DNMT1 at Ser127. AKT additionally phosphorylates Ser143. This modification decreases the ability of DNMT1 to interact with PCNA and UHRF1. As a consequence, DNMT1 shows increased cell-cycle-dependent stability (Esteve et al., 2011).

\subsection{DNMT2}

DNMT2 is expressed in most human and mouse adult tissues (Goll \& Bestor, 2005) and its role seems to be related to methylation of cytosine 38 (C38) of RNAAsp (Goll et al., 2006). There are no strong evidence on DNA methylation activity of DNMT2. The Dnmt2 defficient mouse embryonic stem cells do not show measurable alteration of genomic DNA methylation pattern (Okano et al., 1998). Additionally, in contrast to exclusive nuclear localization of Dnmt1 and Dnmt3, Dnmt2 is primarily localized in the cytoplasm of transfected mouse 3 T3 fibroblasts (Goll et al., 2006).

The level of DNMT2 expression in human cancer cell line is quite variable: high in K562 (leukemia) and MCF-7 (breast cancer) and very low, almost undetectable in A549 (lung cancer ) and HepG2 cells (liver cancer) (Schaefer et al., 2009). It has been shown that the treatment with 5-azacytidine inhibits C38 methylation at RNAAsp. These findings open the possibility that DNMT2 may contribute to neoplastic process through a novel pathways, related to RNA methylation. Clearly, much research should be performed in this area in order to understand all possible roles of DNMT2.

\subsection{DNMT3 family}

In mature cells which divide, DNMT1 is predominant DNA methyltransferase. However, there are two other DNMTs, DNMT3a and DNMT3b, which cannot differentiate between unmethylated and hemimethylated $\mathrm{CpG}$ sites. Their role is primarily de novo DNA methylation. Accordingly, they are highly expressed in early embryonic cells when programmed waves of de novo methylation occur. Their level is considerably lower after differentiation and in adult somatic tissues, but it significantly increases in cancer cells. Both enzymes contain large N-terminal parts which interact with other proteins. The C-terminal domain represents the catalytic center (Gowher \& Jeltsch, 2002). In 1999, mice with targeted disruption of the Dnmt3a and Dnmt3b genes was an excellent model for exploring the activity of these two enzymes. Experiments showed lack of de novo methylation in embryonic stem cells and early embryos but without any effect on the maintenance of imprinted methylation patterns (Okano et al., 1999).

\subsubsection{DNMT3B}

The significance of this enzyme in cancer has been well recognized. The most recent research publications present its role in silencing tumor suppressor genes, through methylation of their promoters. In a study of hepatocellular carcinoma, DNMT3B overexpression was correlated to the level of promoter methylation and expression of MTSS1 (Metastasis Suppressor 1). There was negative correlation with DNMT3B expression and MTSS1 expression, but not with its promoter methylation. The DNMT3B was found to 
be directly bound to the $5^{\prime}$-flanking MSS1 region that was sparsely methylated and methylation inhibitors failed to recover the MSS1 expression. Based on these findings, the conclusion was that DNMT3B may repress MTSS1 through a DNA methylationindependent mechanism (Fan et al., 2011). This should not be surprising, keeping in mind that different protein complexes include the DNMT3B. The thought is that DNMT3B, through a partnership with a transcription repressive complex, inhibits gene expression without necessarily exhibiting its genuine de novo methyltransferase function.

\subsubsection{DNMTs in cancer}

As shown in a comprehensive review in 2011, incorporating most available data relating to the level of DNMTs in cancer, these enzymes are increased in all tested cancer clinical specimens and cancer cell lines (Daniel et al., 2011). The methods used for the quantification were primarily Real-Time PCR and immunochistochemical methods, or both. When we perform these experiments, we must question: Does the amount of mRNA reflect the amount of the protein? Can we reach any conclusion without measuring protein activity? On all these, the answer is, or should be, a resounding "no". However, it has happened all too many times that we do not see clearly and that we reach our conclusion prematurely. If premature - then it is, unfortunately often - wrong. The consequence of all too many examples of this kind of unfortunate mistake is an enormous waste of time, as it takes years to get back on the right track. Many recently retracted papers, including those published in journals with the highest impact factors, are extremely consequential. Many researchers who are initially on the right path, change their hypotheses after reading what they had been led to believe, mistakenly, to be a break-through article. This mistaken action took them straight into the disaster zone of irreproducible results. It takes years for an article to be retracted. Meanwhile, many scientific careers are damaged in an effort to reproduce a result that cannot be reproduced.

\section{Cancer and global DNA hypomethylation}

The reasons for global DNA hypomethylation combined with hypermethylation at many $5^{\prime}$ gene or promoter regions in cancer is not understood. In prior years, research related to this phenomenon was performed on several models: prostate carcinomas, Wilms's tumors and gastric cancer (Ehrlich et al., 2002; Kaneda et al., 2004; Santourlidis et al., 1999). In order to clarify this phenomenon, Ehrlich and co-workers analyzed the relationship of cancer-linked hypermethylation and hipomethylation at 55 gene loci (mostly CpG islands overlapping the $5^{\prime}$ promoter regions), three classes of repetitive elements and global hypomethylation profile in epithelial ovarian malignant tumors (19 ovarian carcinomas, 20 LMP (low malignant potential) tumors and 21 cystadenomas) (Ehrlich et al., 2006). They proved that promoter $5^{\prime}$ gene hypermethylation and both satellite or global DNA hypomethylation occur independently. This was shown in a multivariate regression analysis where, in a final model, hypermethylation variables and hypomethylation variables independently predicted the degree of malignancy in ovarian tumors as follows: LTB4R $(\mathrm{P}<0.005)$, MTHFR 1 $(\mathrm{P}=0.006), C D H 1(\mathrm{P}=0.005)$ and Sat $\alpha(\mathrm{P}=0.005)$. After making an adjustment for multiple comparisons, the LTB4R and MTHFR1 showed an association of DNA methylation with DNMT1 mRNA levels $(\mathrm{P}<0.01)$, in carcinomas. However, this association was not seen when combining them with LMP tumors. 
These examples lead to the following thought: if the total amount of the enzyme is increased, and the system is (globally) hypomethylated, then something has to impact its function. The focus should be on protein interactions because, as shown very recently, the interaction between DNMT1, PCNA and UHFR1 may be disrupted in human and mice astrocytes and glial progenitor cells. This specific change was shown to be an oncogenic event (Hervouet et al., 2010). The same paper shows that gliomagenesis relates to the decrease of 5-mC, the expression level of Dnmt1 remains stabile, but the catalytic activity of the enzyme decreases. This knowledge was applied to analyses measuring maintaining DNMT1 activity in 45 glioma patients who were divided into two groups: those with low $(\mathrm{N}=23)$, and those with high level of methyltransferase activity $(\mathrm{N}=22)$. Very significant differences in survival time was found between these two groups $(\mathrm{p}=0.0019)$, indicating that the level of DNMT1 activity, rather than the absolute amount, could be used as a survival prognostic factor. However, this conclusion must be taken with caution because of the limited number of patients. The results also clearly show that DNMT1/PCNA/UHRF1 interactions inversely correlate with the level of DNMT1 phosphorylation, reflecting, as proved in the cited paper, that the DNMT1 phosphorylation represents the hallmark of DNMT1/PCNA/UHRF1 interaction. The loss of this interaction represents a milestone for chromosomal instability induced by hypomethylated DNA repeat elements and also mediates overexpression of several very potent oncogenes such H-ras and survivin. However, it has to be noted, once again, that the number of patients was rather small and more research, based on a larger number of patients, must be performed in order to convert very strong indications into conclusions relating to DNMT1 phosphorylation as a prognostic cancer marker.

\section{Loss of Imprinting (LOI) and cancer}

Genomic imprinting is an epigenetic phenomenon that ensures monoallelic gene expression in a parent-of-origin dependent manner. Accordingly, imprinted genes are expressed only from a paternal or maternal allele. If we consider the biallelic expression as a full activity of a certain gene, then the imprinted gene gives "half" of the information which makes it very vulnerable to pathogenetic processes. If the gene is biallelically expressed, then any kind of damage affecting one allele still leaves $50 \%$ of overall function. As is the case with tumor suppressor genes, this may be sufficient for normal functioning. If the same happens with the active copy of the imprinted gene, the other allele, silenced through established imprinting marks, cannot add to the functioning. Hence, there is a haplo-insufficiency related to imprinted genes that makes them more "vulnerable".

\subsection{Regulation of genomic imprinting}

Estimation of the total number of imprinted genes in the human genome varies according to the methodology used. There are $\sim 100$ imprinted genes in the mammalian genome and $\sim 70$ imprinted genes have been experimentally verified and catalogued (Morison et al., 2001). These genes are not randomly scattered throughout the genome. They are clustered in the domains containing regulatory DNA elements - imprinting control regions, ICRs. These cisregulatory elements are methylated only on one allele and that is the reason for calling them differentially methylated regions/domains, DMRs/DMDs. DNMT1 has the most important role in DNA methylation maintenance at ICRs. In addition to DNA methylation, other 
epigenetic modifications (post-translational histone tail modifications, binding of polycomb proteins, non-coding RNAs) play an important role in regulating ICRs.

\subsection{IGF2/H19 imprinting}

IGF2, coding for IGF2 mitogenic peptide and H19, a protein non-coding gene, at the human chromosome 11p15.5, are reciprocally imprinted, in most tissues studied to date. This is controlled by the IGF2/H19 ICR which lies upstream of H19 and is methylated only on the paternal allele (Tremblay et al., 1997). Accordingly, H19 promoter is also methylated on the paternal allele and H19 is silent (Zhang et al, 1993).

The insulator model (Figure 1) describes, roughly, how IGF2/H19 ICR regulates monoallelic expression of IGF2 and H19. The insulators are DNA sequences which block contact between promoters and nearby enhancers/silencers. The IGF2/H19 ICR is positioned between IGF2 and H19, 100 kb downstream of the IGF2. The downstream enhancers are shared by IGF2 and H19 (Leighton et al., 1995). On the maternal allele, the CCCTC binding factor (CTCF) binds to unmethylated IGF2/H19 ICR and insulates Igf2 promoters from the enhancers (Bell \& Felsenfeld, 2000; Hark et al., 2000). The human IGF2/H19 ICR region has seven CTCF binding sites, but only the methylation of the sixth one acts as a key regulatory domain (Takai et al., 2001) through abolishing the CTCF binding to the paternal IGF2/H19 ICR, leading to IGF2 expression (Bell \& Felsenfeld, 2000; Hark et al., 2000). In humans, the CTCF binding to both IGF2/H19 ICR and the IGF2 promoters P2-P4, and insulation of the IGF2 promoters from enhancers on the maternal allele, involves long-range intrachromosomal interactions (Vu et al., 2010).

\section{a) Paternal IGF2/H19 allele}

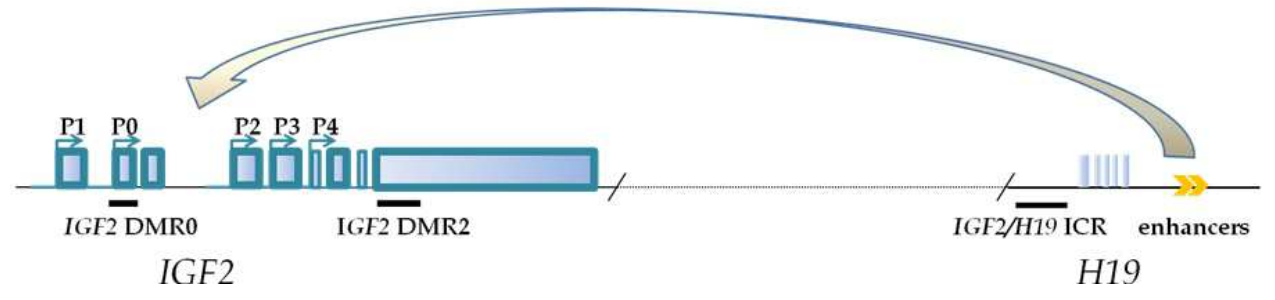

\section{b) Maternal IGF2/H19 allele}

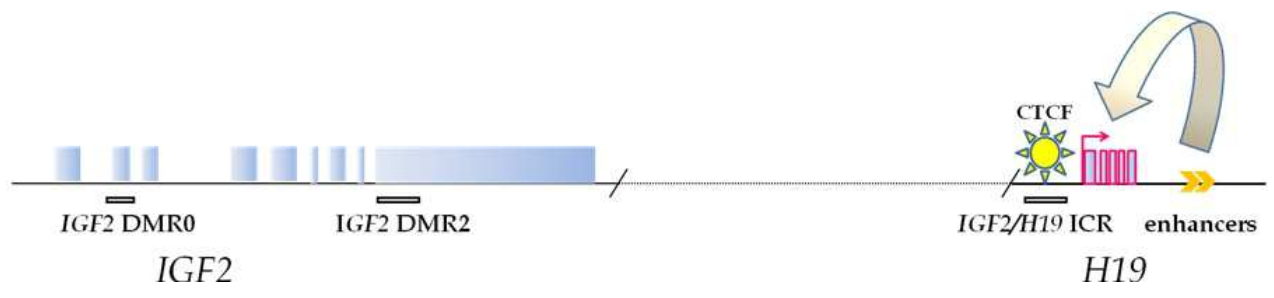

Fig. 1. The insulator model. Arrows: Five IGF2 promoters and a H19 promoter; shaded boxes: nine IGF2 (lined blue) and five H19 (lined pink) exons. Black filled lines: DMR0, DMR2 and IGF2/H19 ICR, shown below the exons as (methylated) on the paternal allele, and without any fill (unmethylated) on the maternal allele. Orange arrowheads: enhancers. Yellow sun: CTCF. 
In humans, there are still some missing links relating to IGF2/H19 imprinting mechanisms. One of them includes two additional differentially methylated regions (Figure 1): DMR0, surrounding IGF2 promoter P0 and methylated on the paternal allele (Murrell et al., 2008) and DMR2, in IGF2 exon 9 (Murrell et al., 2008). DMR0 does not bind CTCF (Vu et al., 2010). The existence of two additional imprinted genes in this region IGF2AS (Okutsu et al., 2000), and PIHit (paternally expressed Igf2/H19 intergenic transcript) (Court et al., 2011) adds even more complexity to the whole chromosomal locus; together with the CTCF paralogue, BORIS/CTCFL (Brother of Regulator of Imprinted Sites/CTCF-like) (Loukinov et al., 2002).

Both proteins, CTCF (Uniprot: P49711) and BORIS (Uniprot: Q8NI51), share 74\% homology in their 11-Zn-finger, DNA binding domains. Their $\mathrm{N}^{\prime}$ and $\mathrm{C}^{\prime}$ termini have less than a $10 \%$ sequence homology. This implies that they can bind to the same DNA sequences (for example, IGF2/H19 ICR) but each of them interacts with different protein partners and has different function. For example, BORIS is involved in the establishment of IGF2/H19 imprinting marks in the male germline (Jelinic et al., 2006). CTCF is involved in the interpretation of these imprinted marks in somatic cells (Hore et al., 2008).

\subsection{Loss of imprinting in cancer}

Loss of imprinting (LOI) in cancer is manifested as either activation of normally epigenetically silenced allele resulting in biallelic expression, or as silencing of normally active allele (Table 1; IGF2 and H19 not shown).

\begin{tabular}{|c|c|c|}
\hline Imprinted gene & Cancer type & Reference \\
\hline \multicolumn{3}{|c|}{ Biallelic expression } \\
\hline$I G F 2 A S$ & Wilms' tumor & (Vu et al., 2003) \\
\hline \multirow[t]{2}{*}{ PEG1/MEST } & Invasive breast cancer & (Pedersen et al., 1999) \\
\hline & Lung cancer & (Kohda et al., 2001) \\
\hline LIT1 & Colorectal cancer & (Nakano et al., 2006) \\
\hline$I P W$ & Testicular germ cell tumor & (Rachmilewitz et al., 1996) \\
\hline \multicolumn{3}{|c|}{ Loss of expression } \\
\hline \multirow[t]{2}{*}{ PEG3 } & Glioma & (Maegawa et al., 2001) \\
\hline & $\begin{array}{l}\text { Endometrial, cervical and } \\
\text { ovarian cancer cell lines }\end{array}$ & (Dowdy et al., 2005) \\
\hline \multirow[t]{2}{*}{ PLAGL1/ZAC1 } & Ovarian cancer & (Abdollahi et al., 2003) \\
\hline & Breast cancer & (Abdollahi et al., 2003) \\
\hline ARHI/DIRAS3/NOEY2 & Breast cancer & (Yuan et al., 2003) \\
\hline ITUP1 & Glioma cell lines & (Maegawa et al., 2004) \\
\hline \multirow[t]{2}{*}{ CDKN1C } & Bladder cancer & (Hoffmann et al., 2005) \\
\hline & Lung cancer & (Kondo et al., 1996) \\
\hline MEG3 & Meningioma & (Zhang, X. et al., 2010) \\
\hline
\end{tabular}

Table 1. Imprinted genes - Loss of imprinting in cancer

Theoretically, in the case of imprinted tumor suppressor genes, loss of the expression from only one functional allele could contributes to tumorigenesis by mimicking "the second hit", according to Knudson's Two Hits Hypothesis (Knudson, 1971). The same effect on the cell 
dividing potential and growth has the biallelic expression of the imprinted, growth promoting gene; mice with Igf2 LOI in intestines have less differentiated intestines and develop twice as many adenomas, in comparison with control (Sakatani et al., 2005). This is, of course, simplified presentation which may not be realistic at all due to existence of many different regulating processes and signaling molecules included in the process of carcinogenesis.

\subsubsection{Loss of IGF2 and H19 imprinting in cancer}

IGF2 and H19 LOI has been demonstrated in many different types of cancer (reviewed in Jelinic \& Shaw, 2007). We were the first to analyze the IGF2/H19 imprinting status in laryngeal squamous cell carcinoma samples (LSCCs) (Grbesa et al., 2008) where we detected IGF2 LOI in 33\% of LSCCs and $28 \%$ of adjacent non-tumorous laryngeal tissues. This finding was already discussed. At that time, the IGF2 LOI in normal tissues has been detected only in colon mucosa of patients with colorectal cancer (Cui et al., 2003), and it was also known that IGF2 LOI exists in peripheral blood lymphocytes, in $10 \%$ of normal population (Sakatani et al., 2001). It is difficult to imagine the IGF2 LOI as a cancer biomarker as, presently, we detect LOI at the level of easily degraded mRNA (that needs to be entirely free of DNA). Additional problem presents restriction of analysis to the polymorphic sites (SNP), that are not necessarily informative for certain markers, in certain populations (Kaaks et al., 2009). We have also detected H19 LOI in $23 \%$ of LSCCs, in line with el-Naggar's results (elNaggar et al., 1999). Increased H19 expression in LSCCs was reconfirmed recently (Mirisola et al., 2011).

In a non-tumorous cell, based on the insulator model, one expects existence of MOI (maintenance of imprinting) through monoallelic IGF2 and monoallelic H19 expression. If there is a LOI, the insulator model proposes biallelic expression of IGF2 or H19, and no expression of the partner (for example, IGF2 biallelically expressed, H19 silenced). But, this is not the case. We have detected, in a small subset of samples (2/10) informative for both IGF2 and H19 imprinting analyses, biallelic IGF2 expression (IGF2 LOI) joined with H19 MOI. In remaining eight samples, the imprinting was maintained. This was also observed in a broad group of head and neck cancers (among them, 14 LSCCs) (el-Naggar et al., 1999). Again, we are here facing the challenge related to the presence of "contaminating", nontumorous cell with an open possibility that they contributed to the "mixed" result. The solution could be the usage of methods which enable analysis of IGF2/H19 imprinting in the individual cells (for example RNA fluorescent in situ hybridization).

We have also analyzed the methylation of the $6^{\text {th }}$ CTCF-binding site (CBS6) within the ICR by methylation restriction PCR, MR-PCR (Ulaner et al., 2003a). In the samples with IGF2 and H19 MOI, the CBS6 was hemimethylated, while its methylation appeared aberrant in the tissue samples with IGF2 or H19 LOI (Grbesa et al., 2008). The analysis of CTCF binding to the CBS6 by chromatin immunoprecipitation (ChIP) was not performed due to the well known problem in this part of molecular oncology: the limited amount of tissue. However, based on ours and other groups results, it seems that IGF2 and H19 LOI cannot be explained solely on the basis of the level of CBS6 methylation (Cui et al., 2002) and its occupancy by the CTCF (Ulaner et al., 2003b). In cancer cell lines with IGF2 LOI, the whole 3-D structure of 
the IGF2/H19 locus is dramatically changed, in comparison with normal cells and cancer cells with IGF2 MOI (Vu et al., 2010). As the prototype of the method that should be used for this kind of analysis (The Chromosome Conformation Capture Original Copy Assay (3COC) coupled to QPCR and 3D software analysis) does not represent the standard technique applicable for clinical tissue specimen analyses, it will take some time before implementing this type of research on native clinical material.

\subsubsection{New player on the scene-BORIS}

The BORIS is involved in establishment of methylation marks at paternal IGF2/H19 ICR during spermatogenesis (Jelinic et al., 2006). Its expression has been detected in various cancers and cancer cell lines (D'Arcy et al., 2008; Hoffmann et al., 2006; Hong et al., 2005; Jones et al., 2011; Kholmanskikh et al., 2008; Looijenga et al., 2006; Renaud et al., 2007; Risinger et al., 2007; Smith et al., 2009; Ulaner et al., 2003a; Woloszynska-Read et al., 2007).

In our LSSC samples, BORIS was expressed with both maintained IGF2 and H19 imprinting but also in the samples with IGF2/H19 LOI (Grbesa I, unpublished results). Recently, 23 BORIS transcript variants that may potentially produce 17 BORIS polypeptides were discovered (Pugacheva et al., 2010). In human tissues, polypeptides that correspond to calculated molecular weight of some of the BORIS isoforms, have been detected with polyclonal anti-BORIS antibody (Jones et al., 2011) but the role of different BORIS isoforms in establishment and maintenance of IGF2/H19 imprinting remains to be elucidated.

\section{Poly(ADP-ribosyl)ation in regulation of DNA methylation}

Since the seminal work by Feinberg and Vogelstein pointing to the global hypomethylation in tumor cells (Feinberg \& Vogelstein, 1983), many reports followed documenting aberrant aquisition of methylation marks at discrete loci in the genome, most notably those comprising genes involved in cell cycle control. Such methylation pattern is opposite to the bimodal methylation pattern, characterized by global DNA methylation and hypomethylation of CpG islands, that is physiologically aquired at the time of embryo implantation and faithfully maintained throughout life (Brandeis et al., 1993). The search for cis- and trans-acting factors that orchestrate such bimodal methylation pattern has since been the focus of scientific interest.

Twenty years ago, linker histone $\mathrm{H} 1$ has been identified to have inhibitory effect on DNA methylation (Caiafa et al., 1991). Shortly thereafter, the difference between H1 histone isoforms, at that time termed as "tightly-bound" and "loosely-bound," in regulation of DNA methylation were observed. In contrast to "typical" loosly-bound histone H1, tightly-bound histone H1 has been shown to facilitate methylation of linker DNA (Santoro et al., 1993). The histone H1, which is able to bind CpG-rich DNA sequences and inhibit double-stranded DNA methylation, has later been identified as variant H1e (Santoro et al., 1995) that promotes chromatin condensation or, upon poly(ADP-ribosyl)ation (pARylation), chromatin decondensation (D'Erme et al., 1996). Appart from the importance of this histone variant and its pARylation in chromatin decondensation, which allows recruitment of transcription factors, the same group has demonstrated the mandatory role of pARylation in 
the maintenance of hypomethylated state of $\mathrm{CpG}$ islands in mouse fibroblasts (Zardo \& Caifa, 1998).

Inhibition of pARylation by competitive PARP inhibitor, 3-aminobenzamide (3-AB), enhances DNA metylation (Zardo \& Caifa, 1998). pARylation is process catalyzed by poly(ADP-ribose) polymerases (PARP), which use NAD as a substrate to build up polymers of ADP-ribose on acceptor proteins, including PARP-1 (D'Amours et al., 1999). It is the founding member of this enzyme family, accounting for more than $90 \%$ of cellular pARylating capacity. It is able to form long linear or branched ADP-ribose polymers composed of several up to 200 ADP-ribose units. There are at least 28 sites in PARP-1 automodification domain upon which long and branched ADP-ribose polymers bind (Juarez-Salinas et al., 1982). The negative charge of ADP-ribose polymers makes them resemble nucleic acids and compete with them for binding different protein partners. ADPribose polymers, either covalently linked to acceptor proteins or protein-free, are also able to non-covalently bind proteins (Malanga \& Althaus, 2005). The binding of ADP-ribose polymers to acceptor proteins is dependent on the presence of amino-acids consensus, poly(ADP-ribose)-binding motifs, that allows for non-covalent binding (Pleschke et al., 2000). Those consensuses are present in a wide variety of proteins with very divergent functions, ranging from structural proteins such as histones (Althaus et al., 1995), proteins involved in DNA repair to enzymes involved in regulation of DNA topology (Malanga \& Althaus, 2005). Binding of negatively charged poly(ADP-ribose) polymers functionaly and structuraly modifies acceptor proteins (Panzeter et al., 1992).

The DNMT1 has two amino-acid consensus motifs for binding poly(ADP-ribose) polymers in its N-terminal domain. It was demonstrated that pARylated PARP-1 and DNMT1 form complex in vivo, and that either PARP-1-associated or free poly(ADP-ribose) polymers are able to inhibit catalytic activity of DNMT1 (Reale et al., 2005). The majority of PARP-1 molecules in normal cell is unmodified (D'Amours et al., 1999) and the mechanism directing the minority of, under physiological conditions, automodified PARP-1 molecules to CpG islands remains an open question. In an effort to elucidate the possible involvement of pARylation in the regulation of Dnmt1 gene promoter, Guastafierro et al. (2008) have examined transcription factors known to be subject to covalent poly(ADP-ribosyl)ation (Hassa et al., 2006). Highly conserved multifunctional transcription factor, CTCF (Ohlsson et al., 2001), attracted their attention based on its role in protection of DNA from methylation and functional dependence on pARylation. The key role of pARylation of CTCF in its insulator/ enhancer blocking function has been reported by $\mathrm{Yu}$ et al. in 2004. The role of CTCF in regulation of IGF2/H19 imprinting has been abolished by treatment with PARP-1 inhibitor 3-AB. To establish whether the lack of CTCF pARylation is indeed responsible for the loss of IGF2 imprinting, the association of poly(ADP-ribose) polymers with H19 ICR was examined by ChIP on wild-type and mutant-type ICR containing CTCF-binding sites. The pARylation mark has been present only if the wild-type allele has been inherited maternally. In the lack of specific antibodies recognizing pARylated CTCF, however, it cannot be ruled out that CTCF binding to its target sites is necessary for activation of PARP-1 or other members of poly(ADP-ribose) polymerase family that would pARylate proteins other than CTCF in that region. Indeed, it has been demonstrated that, in addition to its previously recognized characteristic of being acceptor of poly(ADP-ribose) polymers, CTCF is interacting 
with PARP-1 and is able to activate PARP-1 in the absence of DNA nicks, whereby both proteins become pARylated and negatively affect DNA methylation machinery (Guastafierro et al., 2008). The epigenetic regulation of tumor suppressor $p 16^{I N K 4 a}$ provided some insight into CTCF and PARP-1 DNA-binding and the influence of their pARylation relative to the expression of this gene and several other CTCF-regulated genes (Witcher \& Emerson, 2009). Transcription of $p 16^{I N K 4 a}$ depends on CTCF binding to a chromatin boundary $\sim 2 \mathrm{~kb}$ upstream of its transcription start site. In the absence of CTCF binding, $p 16$ is silenced in various types of tumor cells. When associated with the boundary element, in p16-expressing cells, CTCF is pARylated. However, no direct association of pARylated CTCF and PARP-1 could be detected in those p16-expressing cells. In p16-silenced cells, CTCF was not pARylated and bound to the methylated boundary element, but CTCFPARP-1 complex could be readily detected by co-immunoprecipitation. Moreover, the authors found that pARylated CTCF dissociates from PARP-1, whereas pARylated CTCF remains associated with PARP-1 and loses its function, at this boundary element. Therefore, it is conceivable that deregulation of pARylation may impart the aberrant association of CTCF and PARP-1 and change the association of CTCF with its DNA binding sites. Relevant to the possible influence of the CTCFs binding to DNA and its protective role against DNA methylation is the recent report on the ability of CTCF to form an unusual DNA structure (MacPherson \& Sadowski, 2010). Considering that, in addition to the classical view that PARP-1 is activated by DNA nicks, various non-linear DNA structures are able to activate this enzyme (Lonskaya et al., 2005), the property of CTCF to loop DNA may be yet another facet in connecting processes of DNA methylation and poly(ADP-ribosyl)ation.

\section{Epigenomic therapy}

The inhibition of DNMTs has been used in epigenetic cancer therapy, based on the idea that seems to be quite simple: what is hypermethylated, needs to be normomethylated. So, if we consider the act of removing the methylation marks from hypermethylated promoters of tumor suppressor genes whose protein products are involved in regulation of cell cycle, apoptosis and DNA repair as a therapeutic act, we may be well on a right way.

There are two kinds of DNA methylation inhibitors: nucleoside (Fig. 2) and non-nucleoside analogues. The consequences of nucleoside analogue incorporation into DNA (in this situation, in lieu of cytosines) is DNMT binding and blocking, causing depletion of overlay active enzyme molecules with DNA methyltransferase activity. Two DNA methylation inhibitors, cytidine analogs, were approved by the US Food and Administration (FDA), for the treatment of Myelodysplastic Syndrome and certain forms of leukemias: 5-azacytidine (azacytidine, Vidaza ${ }^{\mathrm{TM}}$ ), which was approved in May, 2004 and 5-aza-2'-deoxycytidine (5azaCdR, decitabine, Dacogen ${ }^{\mathrm{TM}}$ ), which is a deoxyribose analog of 5-azacytidine, approved in May, 2006 (Figure 2).

The antineoplastic effects caused by these two drugs are related to targeted DNA demethylation (and consequential restoration of gene activity necessary for differentiation) and a direct cytotoxic effect on abnormal, rapidly dividing hematopoietic cells in the bone marrow. Non-proliferating cells are relatively insensitive to these two drugs, but their inherently toxic effects do produce certain side-effects. 
a)

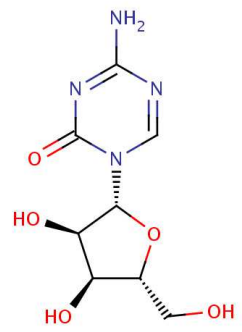

b)

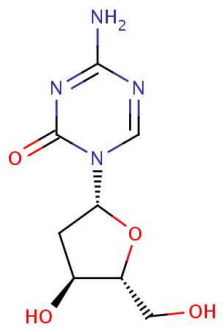

Fig. 2. 5-Azacytidine (a) and 5-Aza-2'-deoxycytidine (b)

\subsection{5-azacytidine and decitabine}

5-azacytidine was described as a DNMT inhibitor more than 30 years ago (Jones \& Taylor, 1980). The first approved clinical targets for 5-azacytidine were Myelodysplastic Syndrome (MDS) and acute myeloid leukema. The drug can be applied subcutaneously or through IV infusion.

This nucleotide analogue becomes incorporated into DNA in place of cytosine after being modified by ribonucleotide reductase and subsequent phosphorylation. When DNMT1 "recognizes" it as a unmethylated substrate in a newly synthesized DNA strand and "approaches" it, it becomes trapped through covalent binding to the incorporated analogue. The reduced level of DNA methylation that follows represents the consequence of passive demethylation in consequent cell cycles due to the lack of functional enzyme. 5-azacytidine can also be phosphorylated by uridine-cytidine kinase and, as such, incorporated into RNA. When applied subcutaneously, it may cause: nausea, anemia, thrombocytopenia, vomiting, pyrexia, leukopenia, diarrhea, injection site erythema, constipation, neutropenia and ecchymosis. Most common adverse reactions through IV application, according to the FDA, included: petechiae, rigors, weakness and hypokalemia.

MDS is also the primary therapeutic indication for Dacogen ${ }^{\mathrm{TM}}$, as in the case with Vidaza ${ }^{\mathrm{TM}}$. The most prominent side-effects associated with Dacogen ${ }^{\mathrm{TM}}$ treatment are neutropenia and thrombocytopenia.

The third analogue, zebularine, has several advantages over the two previously mentioned compounds. It is more stable, highly selective for cancer cells and, hence, far less toxic (Cheng et al., 2004). However, this potential drug seemed to fail after being very successful in a small pilot study, because a very high dosage of the drug were needed to obtain the desired antitumorous effect (Goffin \& Eisenhauer, 2002). In all three cases, the facts which include non-selective DNA targeting resulting in side-effects, were the basis for approaching the problem in a different way. That is, developing compounds which target DNMTs directly, without prior DNA incorporation requirement.

\subsubsection{New methods in exploring activity of methylation inhibitors}

In 2008, Illumina Golden Gate arrays were used for direct characterization of the effects of azacytidine application in three different leukemia cell lines (HEL, HL-60, K562) and ten patients who fulfilled the WHO criteria for MDS. In the cell lines, the effect of the drug on 
DNMT1 protein level differed, the lowest being in HL-60, while HEL cells appeared relatively resistant to DNMT1 depletion. Accordingly, HL-60 was considerably demethylated, while the HEL cell line did not exhibit significant change in global methylation level. After performing an array-based methylation profiling (1,505 CpGs representing 807 cancer-associated genes), the results were very interesting. In untreated cell lines, the number of methylated CpGs exceeded $80 \%$. After treatment, more than $80 \%$ of spots became demethylated, but only in HL60 and K562 cell lines. There was no consistent demethylation trend in HEL cells. Of importance, flow cytometry analysis showed similar overall cell cycle profiles in all three cell lines. The results obtained on patients' samples $(6 / 10$, as six patients completed at least one treatment course consisting of four cycles) differed significantly. In three patients, the methylation levels remained the same, while in three other persons the level of methylation decreased significantly, through a cyclic demethylation, following the cyclic administration of the drug (Stresemann et al., 2008; Stresmann \& Lyko 2008).

In 2011., a genome-scale Infinium analysis (27,578 CG nucleotides; more than 14,475 associated genes) was performed on two human colon cancer cell lines (HCT116 and double knockout (DKO) HCT116, lacking DNMT1 and DNMT3B) and a HL-60 leukemia cell line treated with both azacytidine and decitabine. The bimodal peaks of methylation distribution was found in both treated and untreated cells, representing spots with low and high levels of methylation. These experiments not only showed more potent demethylation activity of decitabine when compared with azacytidine, but also preferential demethylation at specific loci and demethylation resistance of certain number of CGs, in HCT116. The results from these in vitro study shed new light on problems encountered in clinical work with these drugs: not only was the degree of demethylation of the whole genomic DNA higher than gene-specific demethylation (this is something that we do not want to happen, as these drugs were implemented in the clinic in order to demethylate the hypermethylated promoters of tumor suppressor genes), but also the spatial distribution of demethylated CpGs mimicked the distribution found in DKO HCT116. However, when the cluster of cancer-related genes associated CGs was analyzed separately, it turned out that 906 out of 2,125 were hypermethylated and both drugs were very efficient in removing methylation marks. It is hard to distinguish which gene (and joining CGs) represents the clean "cancer-related“ gene. Many genes that were considered to be "inflammatory genes“ or "metabolic genes", turned out to be "cancer genes", as well. One should be careful regarding this kind of clustering because we are currently far away from a complete understanding of how certain signaling proteins/pathways interact, regardless of to which cluster they were primarily asigned.

When performing computational modeling for the presence of transcription factors binding sites in 851 CpGs representing 644 genes, demethylation - sensitive and - resistant CGs showed different types of enrichment. For example, binding sites of Forkhead box (Fox) transcription factors were enriched in demethylation sensitive genes, while basic HelixLoop-Helix transcription factor binding sites turned out to be enriched in demethylation resistant genes (Hagemann et al., 2011).

\subsection{Non-nucleoside compounds}

There are several more, potentially promising, non-nucleoside, candidates. Some of them are well known drugs/healing compounds, such as curcumin. 
- Procaine (a well known local anesthetic) and its derivative, procainamide (a well known drug for treating cardiac arrhythmia) have shown demethylating activity in cancer cell lines of different origin. They were shown to be a specific inhibitors of DNMT1 (Lee et al, 2005). For example, in prostate cancer cells, procainamide restores GSTP1 expression through demethylation of GSTP1 promoter (Lin X et al., 2001). In lung cancer, these drugs induce demethylation of WIF-1 (Wnt Inhibitory Factor) promoter, a negative regulator of the Wnt-signaling pathway (Gao et al., 2009).

- Hydralazine: The methylation inhibitory role was shown to be specifically related to the inhibition of DNMT (Angeles et al., 2005). Its combination with magnesium valproate, seems to be promising in treating different types of malignant disease, including MDS (Candelaria et al., 2011).

- The inhibitory effect of (-)- epigallocatechin-3-gallate (EGCG), the healing compound from green tea, was shown in 2003 (Fang et al., 2003). It was then shown for the first time, that inhibition of DNA methylation can be inhibited by a commonly consumed dietary constituent. At the same time, these results suggested the potential use of EGCG for the prevention of cancer-related gene silencing. The authors measured the DNMT1 catalytic activity and performed molecular modeling of the interaction between EGCG and DNMT1. Finally, they proved reversal of hypermethylation through the reactivation of expression of several genes (RAR, MGMT, p16INK4a, and $h M L H 1)$.

- Genistein, the soy bean isoflavone, was also shown to influence DNMTs. Based on a literature search, there seems to be only one study exploring its efficacy as a DNA methyltransferase inhibitor (Li et al., 2009).

\subsubsection{Curcumin}

Curcumin (diferulolymethane) is the yellow pigment found in the cooking spice turmeric (Curcuma longa linn). Curcumin is a strong inhibitor of the NF- $\kappa B$ signaling pathway (Gupta et al., 2011). Having in mind the central role of NF- $\mathrm{BB}$ in many different signaling pathways, it is not surprising that this compound shows anti-inflammatory, anti-oxidant, antimicrobial and, finally, anticancer activity. Curcumin is currently being investigated for its chemopreventative efficacy in a variety of solid tumors. So far, most of the controlled clinical trials of curcumin are in phase I (Hatcher et al., 2008), suggesting that oral curcumin is more likely to be effective as a therapeutic agent in cancers of the gastrointestinal tract than in other tissues (Sharma et al., 2005). The results of one non-randomized, open-label, phase II clinical trial conducted in the U.S. were published recently, reporting on the first 25 patients with advanced pancreatic cancer. The patients did not receive any concomitant chemotherapy or radiotherapy. There was partial response in one patient and disease stabilization in other patient, for approximately 2.5 years (Dhillon et al., 2008). Another clinical phase I/II trial included 21 gemcitabine-resistant pancreatic cancer patients who received, like in Dhillon's study, 8 grams of curcumin daily, together with gemcitabine-based chemotherapy in this instance. This combination was shown to be "safe and feasible in patients with pancreatic cancer and warrants further investigation into its efficacy" (Kanai et al., 2011).

There are many efforts to improve curcumin's bioavailability. The most recent results reported on nanoparticle curcumin (Theracurmin), show that this form of curcumin can safely increase plasma curcumin levels in a dose-dependent manner at least up to $210 \mathrm{mg}$, without saturating the absorption system (Kanai et al., 2011). 
We have shown that curcumin selectively inhibits the $H 19$ transcription in several different tumor cell lines, but not in non-tumorous cells. We do not think that protein-non-coding H19 mRNA itself necessarily exerts any kind of vital oncogenic or tumor-suppressive function, but we do think that its mRNA presence indicates vivid, globally deregulated cellular transcription (Novak Kujundzic et al., 2008).

It has been confirmed that curcumin interacts directly with 33 proteins, one of them being DNMT1 (Liu et al., 2009). It is considered that this binding causes direct inhibition of the enzyme and represents the molecular basis for the DNA hypomethylating activity of curcumin (Liu et al., 2009).

\section{5-Hydroxymethylcytosine}

As discussed in previous sub-chapters, methylated cytosine entered the spotlight of the international scientific community, primarily due to our understanding of how genes are, or need to be, regulated. We are just entering the era of full appreciation of the importance of one more cytidine modification, discovered in bacteriophage, in 1952. (Wyatt \& Cohen, 1952). It was "rediscovered“ in 1972. in rat tissue, but was neglected because the results did not seem to be reproducible (Penn et al., 1972). However, thanks to knowledge gained during these almost 60 years, combined with advances in technology, we are now learning about a sixth nucleotide in our genome (Münzel et al., 2011). Only two years ago, two papers in Science showed that mammalian DNA contains 5'-hydroxymethylcytosine (hmC; $5 \mathrm{hmC}$; ${ }^{-\mathrm{HOME} d C}$, Figure 3) (Kriaucionis \& Heintz, 2009; Tahiliani et al., 2009).<smiles>Nc1cc[nH]c(=O)n1</smiles>

a)

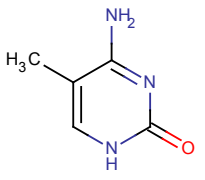

b)

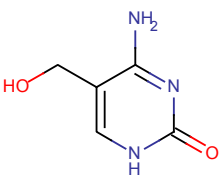

C)

Fig. 3. Cytosine and its modifications.

Unmodified cytosine (a), 5-methylcytosine (b), 5-hydroxymethylcytosine (c).

To date, based on a few in vitro experiments, it has been thought that hmC presents the major oxidative product of mC (Bienvenu et al. 1996; Wagner \& Cadet, 2010).

Ideal for detecting the methylated cytosines, bisulfite fails on $\mathrm{hmC}$. As a result, there is a problem with positioning the sixth nucleotide in the DNA molecule. There is hope from nanopore sequencing, because the first published results show the difference between $\mathrm{mC}$ and hmC in single-, and double-stranded DNA (Wanunu et al., 2011).

So far, most of the work on 5-hmC and TET group of proteins (TET1, TET2 and TET3) was performed on embryonic stem cells and there are only a few papers dealing with "the sixth nucleotide“ in cancer. The TET proteins which can modify 5-methylcytosine in humans were initially discovered through a computational search showing these proteins as 
mammalian homologs of the trypanosome proteins JBP1 and JBP2, the enzymes proposed to oxidize the 5-methyl group of thymine (Tahiliani et al., 2009). Predictably, hmC levels decrease upon RNA interference-mediated depletion of TET1.

The role of hmC in cancer and its role in participating or in creating epigenomic networks, is almost entirely unknown. There are a few, recently published papers, showing its influence on the affinity (a strong decrease) with which the MBD proteins bind to DNA "occupied“ by $\mathrm{hmC}$. The 5-hmC immunoassay (developed by Liu at coworkers) was applied to various healthy human tissues and four cancer cell lines. The differences in $\mathrm{hmC}$ content among the tested cell lines were minor and insignificant. The tissue analyses showed that brain tissue has the highest content of hmC. Among all tissues tested, the lowest level was detected in lung, breast and placenta. When compared with $\mathrm{mC}$ distribution in various tissues (which published data showed a range of 1-2.5), the differences in hmC tissue-specific content were very strong. In cancer tissues, when compared to adjacent, non-tumorous tissue, the level of hmC was significantly lower; in one case 7.7-fold, in the other 28 -fold (Li \& Liu, 2011). So, the question was asked: is it possible that this increase occurs because the global level of methylated cytosines decreases in cancer cells?

Part of the answer was given in a paper published in September, 2011 (Haffner et al., 2011). The authors analyzed 78 carcinomas and 28 normal tissue samples (prostate, breast and colon). They have shown, by using immunohistochemical staining they developed, a significant decrease of $\mathrm{hmC}$ in tumorous tissues. There was also a significant difference in $\mathrm{hmC}$ tissue distribution: in normal tissue, the signals were strongest in the terminally differentiated luminal cells and far less strong in basal cells. In cancer tissues, the differences were very clear at the border between the tumor and non-tumorous tissue. However, although very prominent, these changes did not allow for any association with clinicopathological features, including the tumor grade (level of differentiation). Although there is a significant similarity between Haffner's and Li's result, the methods they used were quite different, which - to be sure, does not diminish the quality and importance of their results. In any event, the hmC story will need to be explored on many clinical samples before we allow ourselves to conclude anything about their prognostic significance in cancer patients.

Williams and colleagues published a very extensive study on TET protein family member function, showing the necessity of TET1 time-specific expression during development. In their experimental model, TET1 localized to both gene bodies and transcription start sites (TSS), being especially enriched at genes with high CpG content, while mC localized in regions with low $\mathrm{CpG}$ content. The results indicate "that TET1, by converting $\mathrm{mC}$ to $\mathrm{hmC}$ serves an important function in the regulation of DNA methylation fidelity" (Willimas et al., 2011). What, one should ask, is the consequence of the $\mathrm{hmC}$ presence in the gene promoters/bodies? It seems that, in a pure in vitro system, based on CMV promoter and HeLa cells extracts, the presence of hmCs in the gene promoter inhibits transcription, while their presence in the gene body does not directly inhibit transcription (Robertson et al., 2011).

\section{Conclusion}

In this chapter, we have covered aspects of deregulated DNA methylation in cancer, including a review of older data and introducing the most recent findings. By using this 
approach, we have tried to show maybe the most intriguing and certainly the most emerging aspects of molecular biology of a cancer cell, at the time of preparing this chapter. Certainly, the new exciting discoveries in the field of cancer epigenomics that we are presenting here are only part of emerging sets of data. The new papers with exciting findings are coming to scientific community almost on a daily base does and, for that reason, we did not allow to ourselves offering any hard conclusion, at this time period. We are aware that there are many more issues and mechanisms for discussion, such as the interactions of DNA and proteins, methylation related and unrelated, that we did not discuss. For that reason, we all look forward to future books and articles providing insight on these and like topics.

\section{Acknowledgement}

We are grateful to Dr. Višnja Stepanić and Mr. Zlatko Pandžić for their technical help in preparing this chapter. Our special thanks go to Mr. Aaron Etra who helped us with a careful revision of the text. Our research is supported by grant \#098-0982464-2511 (PI:KGT), from the Ministry of Science, Education and Sport of the Republic of Croatia.

\section{References}

Aapola, U., Kawasaki, K., Scott, H.S. et al. (2000). Isolation and initial characterization of a novel zinc finger gene, DNMT3L, on 21q22.3, related to the cytosine-5methyltransferase 3 gene family. Genomics, Vol.65, No.3, (May 2000), pp. 293-298, ISSN 0888-7543

Althaus, F.R., Bachmann, S., Hofferer, L. et al. (1995). Interactions of poly(ADP-ribose) with nuclear proteins. Biochimie, Vol.77, No.6, pp. 423-432, ISSN 0300-9084

Angeles, E., Vazquez-Valadez, V.H., Vazquez-Valadez, O. et al. (2005). Computational studies of 1-Hydrazinophtalazine (Hydralazine) as antineoplastic agent. Docking studies on methyltransferase. Letters in Drug Design \& Discovery, Vol.2, No 4, (June 2005), pp. 282-286, ISSN: 1570-1808

Asada, K., Asada, R, Yoshiji, H. et al. (2006). DNA cytosine methylation profile in various cancer-related genes is altered in cultured rat hepatocyte cell lines as compared with primary hepatocytes. Oncology Reports, Vol.15, No.5, (May 2006), pp. 12411248, ISSN 1021-335X

Baylin, S.B. \& Jones, P.A.( 2011). A decade of exploring the cancer epigenome - biological and translational implications. Nature Reviews. Cancer. Vol.11, No.10, (September 2011), pp. 726-734, ISSN 1474-175X

Bell, A.C. \& Felsenfeld, G. (2000). Methylation of a CTCF-dependent boundary controls imprinted expression of the Igf2 gene. Nature, Vol.405, No.6785, (May 2000), pp. 482-485, ISSN 0028-0836

Bienvenu, C., Wagner, J.R. \& Cadet, J. (1996). Photosensitized oxidation of 5-Methyl-24deoxycytidine by 2-Methyl-1,4-naphthoquinone: Characterization of 5(Hydroperoxymethyl)-2'-deoxycytidine and stable methyl group oxidation product. Journal of the American Chemical Society, Vol.118, No.46, (November 1996), pp. 11406-11411, ISSN 0002-7863 
Biniszkiewicz, D., Gribnau, J., Ramsahoye, B. et al. (2002). Dnmt1 overexpression causes genomic hypermethylation, loss of imprinting, and embryonic lethality. Molecular and Cellular Biology, Vol.22, No.7, (April 2002), pp. 2124-2135, ISSN 0270-7306

Bock, C., Walter, J., Paulsen, M., Lengauer, T. (2007). CpG island mapping by epigenome prediction. PloS Computational Biology, 3(6):e110., doi: 10.1371/journal.pcbi.0030110, ISSN 1553-734X

Boehm, T.L. \& Drahovsky, D. (1981). Hypomethylation of DNA in Raji cells after treatment with N-methyl-N-nitrosourea. Carcinogenesis, Vol.2, No.1, (January 1981), pp. 39-42, ISSN 0143-3334

Bostick, M., Kim, J., Estève, P-O. et al. (2007). UHRF1 plays a role in maintaining DNA methylation in mammalian cells. Science, Vol.317, No.5845, (September 2007), pp. 1760-1764, ISSN 0036-8075

Brandeis, M., Ariel, M. \& Cedar, H. (1993). Dynamics of DNA methylation during development. BioEssays: News and Reviews in Molecular, Cellular and Developmental Biology, Vol.15, No.11, (November 1993), pp. 709-713, ISSN 0265-9247

Broët, P., Dalmasso, C., Tan, E.H. et al. (2011). Genomic profiles specific to patient ethnicity in lung adenocarcinoma. Clinical Cancer Research, Vol.17, No.11, (June 2011), pp. 3542-3550, ISSN 1078-0432

Caiafa, P., Reale, A., Allegra, P. et al. (1991). Histones and DNA methylation in mammalian chromatin. Differential inhibition by histone H1. Biochimica et Biophysica Acta, Vol.1090, No.1, (August 1991), pp. 38-42, ISSN 0006-3002

Candelaria, M., Herrera, A., Labardini, J. et al. (2011) Hydralazine and magnesium valproate as epigenetic treatment for myelodysplastic syndrome. Preliminary results of a phase-II trial. Annals of Hematology, Vol.90, No.4. (April 2011), pp 379-87, ISSN 09395555

Cheng, J.C., Yoo, C.B., Weisenberger, D.J. et al. (2004). Preferential response of cancer cells to zebularine. Cancer Cell, Vol.6, No.2, (August 2004), pp. 151-158, ISSN 1535-6108

Choi, S.H., Heo, K., Byun, H-M., An, W. Lu, W., Yang, A.S. Identification of preferential target sites for fuman DNA methyltransferases. (2010). Nucleic Acids Research, Vol.39, No.1, (September 2010), pp. 104-118, ISSN 0305-1048

Court, F., Baniol, M., Hagege, H. et al. (2011). Long-range chromatin interactions at the mouse Igf2/H19 locus reveal a novel paternally expressed long non-coding RNA. Nucleic Acids Research, Vol.39, No.14, (August 2011), pp. 5893-5906, ISSN 0305-1048

Cui, H., Onyango, P., Brandenburg, S. et al. (2002). Loss of imprinting in colorectal cancer linked to hypomethylation of H19 and IGF2. Cancer Research, Vol.62, No.22, (November 2002), pp. 6442-6446, ISSN 0008-547

Cui, H., Cruz-Correa, M., Giardiello, F.M. et al. (2003). Loss of IGF2 imprinting: a potential marker of colorectal cancer risk. Science, Vol.299, No.5613, (March 2003), pp. 17531755, ISSN 0036-8075

D’Erme, M., Zardo, G., Reale, A. et al (1996). Co-operative interactions of oligonucleosomal DNA with the H1e histone variant and its poly(ADP-ribosyl)ated isoform. The Biochemical Journal, Vol.316, No.2, (June 1996), pp. 475-480, ISSN 0264-6021

D'Amours, D., Desnoyers, S., D'Silva, I. et al. (1999). Poly(ADP-ribosyl)ation reactions in the regulation of nuclear functions. The Biochemical Journal, Vol.342, No.2, (September 1999), pp. 249-268, ISSN 0264-6021 
Daniel, F.I., Cherubini, K., Yurgel, L.S. et al. (2011). The role of epigenetic transcription repression and DNA methyltransferases in cancer. Cancer, Vol.117, No.4, (February 2011), pp. 677-687, ISSN 0008-543X

D'Arcy, V., Pore, N., Docquier, F. et al. (2008). BORIS, a paralogue of the transcription factor, CTCF, is aberrantly expressed in breast tumours. British Journal of Cancer, Vol.98, No.3, (February 2008), pp. 571-579, ISSN 0007-0920

Dhillon, N., Aggarwal, B.B., Newman, R.A. et al. (2008). Phase II trial of curcumin in patients with advanced pancreatic cancer. Clinical Cancer Research, Vol.14, No.14, (July 2008), pp. 4491-4499, ISSN 1078-0432

Ehrlich, M. (2009). DNA hypomethylation in cancer cells. Epigenomics, Vol1, No.2, (December 2009), pp. 239-259, ISSN 1750-1911

Ehrlich, M., Jiang, G., Fiala, E. et al. (2002). Hypomethylation and hypermethylation of DNA in Wilms tumors. Oncogene, Vol.21, No.43, (September 2002), pp. 6694-6702, ISSN 0950-9232

Ehrlich, M., Woods, C.B., Yu, M.C. et al. (2006). Quantitative analysis of associations between DNA hypermethylation, hypomethylation, and DNMT RNA levels in ovarian tumors. Oncogene, Vol.25, No.18, (March 2006), pp. 2636-2645, ISSN 09509232

El-Naggar, A.K., Lai, S., Tucker, S.A. et al. (1999). Frequent loss of imprinting at the IGF2 and H19 genes in head and neck squamous carcinoma. Oncogene, Vol.18, No.50, (November 1999), pp. 7063-7069, ISSN 0950-9232

Espada, J. \& Esteller, M. (2007). Epigenetic control of nuclear architecture. Cellular and Molecular Life Sciences, Vol.64, No.4, (February 2007), pp. 449-457, ISSN 1420-682X

Estève, P.O., Chang, Y., Samaranayake, M. et al. (2011). A methylation and phosphorylation switch between an adjacent lysine and serine determines human DNMT1 stability. Nature Structural \& Molecular Biology, Vol.18, No.1, (January 2011), pp. 42-48, ISSN 1545-9985

Fan, H., Chen, L., Zhang, F. et al. (2011). MTSS1, a novel target of DNA methyltransferase 3B, functions as a tumor suppressor in hepatocellular carcinoma. Oncogene, in press, doi: 10.1038/onc.2011.411. ISSN 0950-9232

Fang, M.Z., Wang, Y. \& Ai, N. (2003). Tea polyphenol (-)-epigallocatechin-3-gallate inhibits DNA methyltransferase and reactivates methylation-silenced genes in cancer cell lines. Cancer Research, Vol.63, No.22, (November 2003), pp. 7563-7570, ISSN 00085472

Feinberg, A.P. \& Vogelstein, B. (1983). Hypomethylation distinguishes genes of some human cancers from their normal counterparts. Nature, Vol.301, No.5895, (January 1983), pp. 89-92, ISSN 0028-0836

Gall Trošelj, K. \& Novak Kujundžić, R. (2010). Epigenomics - A Bird's Eye Perspective on the Genome. Periodicum Biologorum, Vol.112, No.4, (December 2010), pp. 411-418, ISSN 0031-5362

Gao, Z., Xu, Z., Hung, M.S. et al. (2009). Procaine and procainamide inhibit the Wnt canonical pathway by promoter demethylation of WIF-1 in lung cancer cells. Oncology Reports, Vol.22, No.6, (December 2009), pp. 1479-1484, ISSN 1021-335X

Gardiner-Garden, M. \& Frommer, M. (1987). CpG islands in vertebrate genomes. Journal of Molecular Biology, Vol.196, No.2, (July 1987), pp. 261-282, ISSN 0022-2836 
Goffin, J. \& Eisenhauer, E. (2002). DNA methyltransferase inhibitors - state of the art. Annals of Oncology, Vol.13, No.11, (November 2002), pp. 1699-1716, ISSN 0923-7534

Goll, M.G. \& Bestor, T.H. (2005). Eukaryotic cytosine methyltransferases. Annual Review of Biochemistry, Vol.74, (July 2005), pp. 481-514, ISSN 0066-4154

Goll, M.G., Kirpekar, F., Maggert, K.A. et al. (2006). Methylation of tRNAAsp by the DNA methyltransferase homolog Dnmt2. Science, Vol.311, No.5759, (January 2006), pp. 395-398, ISSN 0036-8075.

Gowher, H. \& Jeltsch, A. (2002). Molecular enzymology of the catalytic domains of the Dnmt3a and Dnmt3b DNA methyltransferases. Journal of Biological Chemistry, Vol.277, No.23, (June 2002), pp. 20409-20414, ISSN 0021-9258

Grbesa, I., Marinkovic, M., Ivkic, M. et al. (2008). Loss of imprinting of IGF2 and H19, loss of heterozygosity of IGF2R and CTCF, and Helicobacter pylori infection in laryngeal squamous cell carcinoma. Journal of Molecular Medicine (Berlin), Vol.86, No.9, (September 2008), pp. 1057-1066, ISSN 0946-2716

Guastafierro, T., Cecchinelli, B., Zampieri, M. et al. (2008). CCCTC-binding factor activates PARP-1 affecting DNA methylation machinery. Journal of Biological Chemistry, Vol.283, No.32, pp. 21873-21880, ISSN 0021-9258.

Gupta, S.C., Kim J.H., Kannappan, R. et al. (2011). Role of nuclear factor кB-mediated inflammatory pathways in cancer-related symptoms and their regulation by nutritional agents. Experimental Biology and Medicine. Vol.236, No.6, (June 2011), pp. 658-671, ISSN 1535-3702

Haffner, M.C., Chaux, A., Meeker, A.K. et al. (2011). Global 5-hydroxymethylcytosine content is significantly reduced in tissue stem/progenitor cell compartments and in human cancers. Oncotarget, Vol.2, No.8, (September 2011), pp. 627 - 637, Online ISSN: 1949-2553

Hagemann, S., Heil, O., Lyko, F. et al. (2011). Azacytidine and decitabine induce genespecific and non-random DNA demethylation in human cancer cell lines. PLoS ONE, 6(3):e17388. doi:10.1371/journal.pone.0017388, ISSN 1932-6203

Hark, A.T., Schoenherr, C.J., Katz, D.J. et al. (2000). CTCF mediates methylation-sensitive enhancer-blocking activity at the H19/Igf2 locus. Nature, Vol.405, No.6785, (May 2000), pp. 486-489, ISSN 0028-0836

Hassa, P.O., Haenni, S.S., Elser, M. et al. (2006). Nuclear ADP-ribosylation reactions in mammalian cells: where are we today and where are we going? Microbiology and Molecular Biology Reviews: MMBR, Vol.70, No.3, (September 2006), pp. 789-829, ISSN 1092-2172

Hatcher, H., Planalp, R., Cho, J. et al. (2008). Curcumin: from ancient medicine to current clinical trials. Cellular and Molecular Life Sciences, Vol.65, No.11, (June 2008), pp. 1631-1652, ISSN 1420-682X

Hervouet, E., Lalier, L., Debien, E. et al. (2010). Disruption of Dnmt1/PCNA/UHRF1 interactions promotes tumorigenesis from human and mice glial cells. PLoS ONE, 5(6): e11333. doi: 10.1371/journal.pone.0011333, ISSN 1932-6203

Hervouet, E., Vallette, F.M. \& Cartron, P-F. (2010). Impact of the DNA methyltransferases expression on the methylation status of apoptosis-associated genes in glioblastoma multiforme. Cell Death $\mathcal{E}$ Disease, 1(1):e8, doi: 10.1038/cddis.2009.7, ISSN 2041-4889 
Hoffmann, M.J., Florl, A.R., Seifert, H.H. et al. (2005). Multiple mechanisms downregulate CDKN1C in human bladder cancer. International Journal of Cancer, Vol.114, No.3, (April 2005), pp. 406-413, ISSN 0020-7136

Hoffmann, M.J., Muller, M., Engers, R. et al. (2006). Epigenetic control of CTCFL/BORIS and OCT4 expression in urogenital malignancies. Biochemical Pharmacology, Vol.72, No.11, (November 2006), pp. 1577-1588, ISSN 0006-2952

Holliday, R. \& Pugh, J.E. (1975). DNA modification mechanisms and gene activity during development. Science, Vol.187, No.4173, (January 1975), pp. 226-232, ISSN 0036-8075

Hong, J.A., Kang, Y., Abdullaev, Z. et al. (2005). Reciprocal binding of CTCF and BORIS to the NY-ESO-1 promoter coincides with derepression of this cancer-testis gene in lung cancer cells. Cancer Research, Vol.65, No.17, (September 2005), pp. 7763-7774, ISSN 0008-5472

Huang, Y.W., Kuo, C.T., Stoner, K., Huang, T.H., Wang, L.S. (2011). An overview of epigenetics and chemoprevention. FEBS Letters. Vol.585, No.13, (July 2011), pp. 2129-2136, ISSN 0014-5793

Jelinic, P. \& Shaw, P. (2007). Loss of imprinting and cancer. The Journal of Pathology, Vol.211, No.3, (February 2007), pp.261-268, ISSN 0022-3417

Jelinic, P., Stehle, J.C. \& Shaw, P. (2006). The testis-specific factor CTCFL cooperates with the protein methyltransferase PRMT7 in H19 imprinting control region methylation. PLoS Biology, 4(11): e355. doi:10.1371/journal.pbio.0040355, ISSN 1544-9173

Jones, P.A. \& Taylor, S.M. (1980). Cellular differentiation, cytidine analogs and DNA methylation. Cell, Vol.20, No.1, (May 1980), pp. 85-93, ISSN 0092-8674

Jones, T.A., Ogunkolade, B.W., Szary, J. et al. (2011). Widespread expression of BORIS/CTCFL in normal and cancer cells. PloS ONE, 6(7): e22399. doi:10.1371/journal.pone.0022399, ISSN 1932-6203

Juarez-Salinas, H.L.V., Jacobson, E.L. \& Jacobson, M.K. (1982). Poly(ADP-ribose) has a branched structure in vivo. Journal of Biological Chemistry, Vol.257, No.2, pp. 607609, (January 1982), ISSN 0021-9258

Kaaks, R., Stattin, P., Villar, S. et al. (2009). Insulin-like growth factor-II methylation status in lymphocyte DNA and colon cancer risk in the Northern Sweden Health and Disease cohort. Cancer Research, Vol.69, No.13, (July 2009), pp. 5400-5405, ISSN 0008-5472

Kanai, M., Imaizumi, A., Otsuka, Y. et al. (2011) Dose-escalation and pharmacokinetic study of nanoparticle curcumin, a potential anticancer agent with improved bioavailability, in healthy human volunteers. Cancer Chemotherapy and Pharmacology, in press, ISSN 0344-5704

Kanai, M., Yoshimura, K., Asada, M. et al. (2011). A phase I/II study of gemcitabine-based chemotherapy plus curcumin for patients with gemcitabine-resistant pancreatic cancer. Cancer Chemotherapy and Pharmacology, Vol.68, No.1, (July 2011), pp. 157-164, ISSN 0344-5704

Kaneda, A., Tsukamoto, T., Takamura-Enya T. et al. (2004). Frequent hypomethylation in multiple promoter $\mathrm{CpG}$ islands is associated with global hypomethylation, but not with frequent promoter hypermethylation. Cancer Science, Vol.95, No.1, (January 2004), pp. 58-64, ISSN 1347-9032 
Kholmanskikh, O., Loriot, A., Brasseur, F. et al. (2008). Expression of BORIS in melanoma: lack of association with MAGE-A1 activation. International Journal of Cancer, Vol.122, No.4, (February 2008), pp. 777-784, ISSN 0020-7136

Kim, J.Y., Siegmund, K.D., Tavaré, S. et al. (2005). Age-related human small intestine methylation: evidence for stem cell niches. BMC Medicine, 3:10, doi:10.1186/17417015-3-10, ISSN 1741-7015

Knudson, A.G., Jr. (1971). Mutation and cancer: statistical study of retinoblastoma. Proceedings of the National Academy of Sciences of the United States of America, Vol.68, No.4, (April 1971), pp. 820-823, ISSN 0027-8424

Kriaucionis, S. \& Heintz, N. (2009). The nuclear DNA base 5-hydroxymethylcytosine is present in Purkinje neurons and the brain. Science, Vol.324, No.5929, (May 2009), pp. 929-930, ISSN 0036-8075

Lee, B.H., Yegnasubramanian, S., Lin, X. et al. (2005). Procainamide is a specific inhibitor of DNA methyltransferase 1. Journal of Biological Chemistry, Vol.280, No.49, (December 2005), pp. 40749-40756, ISSN 0021-9258

Leighton, P.A., Saam, J.R., Ingram, R.S. et al. (1995). An enhancer deletion affects both H19 and Igf2 expression. Genes $\mathcal{E}$ Development, Vol.9, No.17, (September 1995), pp. 20792089, ISSN 0890-9369

Li, W. \& Liu, M. (2011). Distribution of 5-hydroxymethylcytosine in different human tissues. Journal of Nucleic Acids, Vol.286, No.28, (July 2011), pp. 24685-24693, ISSN 0021-9258

Li, Y., Liu, L., Andrews, L.G. et al. (2009). Genistein depletes telomerase activity through cross-talk between genetic and epigenetic mechanisms. International Journal of Cancer, Vol.125, No.2, (July 2009), pp. 286-296, ISSN 0020-7136

Lin, X., Asgari, K., Putzi, M.J. et al. (2001). Reversal of GSTP1 CpG island hypermethylation and reactivation of pi-class glutathione S-transferase (GSTP1) expression in human prostate cancer cells by treatment with procainamide. Cancer Research, Vol.61, No.24, (December 2001), pp. 8611-8616, ISSN 0008-5472

Lister, R., Pelizzola, M., Dowen, R.H. et al. (2009). Human DNA methylomes at base resolution show widespread epigenomic differences. Nature, Vol.462, No.7271, (November 2009), pp. 315-322, ISSN 0028-0836

Liu, Z., Xie, Z., Jones, W. et al. (2009). Curcumin is a potent DNA hypomethylation agent. Bioorganic \& Medicinal Chemistry Letters, Vol.19, No.3, (February 2009), pp. 706-709, ISSN 0960-894X

Looijenga, L.H., Hersmus, R., Gillis, A.J. et al. (2006). Genomic and expression profiling of human spermatocytic seminomas: primary spermatocyte as tumorigenic precursor and DMRT1 as candidate chromosome 9 gene. Cancer Research, Vol.66, No.1, (January 2006), pp. 290-302, ISSN 0008-5472

Loukinov, D.I., Pugacheva, E., Vatolin, S. et al. (2002). BORIS, a novel male germ-linespecific protein associated with epigenetic reprogramming events, shares the same 11-zinc-finger domain with CTCF, the insulator protein involved in reading imprinting marks in the soma. Proceedings of the National Academy of Sciences of the United States of America, Vol.99, No.10, (May 2002), pp. 6806-6811, ISSN 0027-8424

Malanga, M. \& Althaus, F.R. (2005). The role of poly(ADP-ribose) in the DNA damage signaling network. Biochemistry and Cell Biology / Biochimie et Biologie Cellulaire, Vol.83, No.3, pp. 354-364, (June 2005), ISSN 0829-8211 
Mirisola, V., Mora, R., Esposito, A.I. et al. (2011). A prognostic multigene classifier for squamous cell carcinomas of the larynx. Cancer Letters, Vol.307, No.1, (August 2011), pp. 37-46, ISSN 0304-3835

Morison, I.M., Paton, C.J. \& Cleverley, S.D. (2001). The imprinted gene and parent-of-origin effect database. Nucleic Acids Research, Vol.29, No.1, (January 2001), pp. 275-276, ISSN 0305-1048

Münzel, M., Globisch, D. \& Carell, T. (2011). 5-Hydroxymethylcytosine, the sixth base of the genome. Angewandte Chemie International Edition, Vol.50, No.29, (July 2011), pp. 6460-6468, ISSN 1521-3773.

Murrell, A., Ito, Y., Verde, G. et al. (2008). Distinct methylation changes at the IGF2-H19 locus in congenital growth disorders and cancer. PloS ONE, 3(3): e1849. doi:10.1371/journal.pone.0001849, ISSN 1932-6203

Ndlovu, M.N., Denis, H., Fuks, F. (2011). Exposing the DNA methylation iceberg. Trends in Biochemical Sciences, Vol.36, No.7, (July 2011), pp. 381-387, ISSN 0968-0004

Novak Kujundžić, R., Grbeša, I., Ivkić, M. et al. (2008). Curcumin downregulates H19 gene transcription in tumor cells. Journal of Cellular Biochemistry, Vol.104, No.5, (August 2008), pp. 1781-1792, ISSN 0730-2312

Ohlsson, R., Renkawitz, R. \& Lobanenkov, V. (2001). CTCF is a uniquely versatile transcription regulator linked to epigenetics and disease. Trends in Genetics: TIG, Vol.17, No.9, (September 2001), pp. 520-527, ISSN 0168-9525

Okano, M., Xie, S., Li, E. (1998). Dnmt2 is not required for de novo and maintenance methylation of viral DNA in embryonic stem cells. Nucleic Acids Research, Vol.26, No.11, (June 1998), pp. 2536-2540, ISSN 0305-1048

Okano, M., Bell, D. W., Haber, D. A. et al. (1999). DNA methyltransferases Dnmt3a and Dnmt3b are essential for de novo methylation and mammalian development. Cell, Vol.99, No.3, (October 1999), pp. 247-257, ISSN 0092-8674

Panzeter, P.L., Zweifel, B., Malanga, M. et al. (1993). Targeting of histone tails by poly(ADPribose). Journal of Biological Chemistry, Vol.268, No.24, (August 1993), pp. 1766217664, ISSN 0021-9258

Penn, N.W., Suwalski, R., O'Riley, C. et al. (1972). The presence of 5-hydroxymethylcytosine in animal deoxyribonucleic acid. Biochemical Journal, Vol.126, No.4, (February 1972), pp. 781-790, ISSN 0264-6021

Pleschke, J.M., Kleczkowska, H.E., Strohm, M. et al. (2000). Poly(ADP-ribose) binds to specific domains in DNA damage checkpoint proteins. Journal of Biological Chemistry, Vol.275, No.52, (December 2000), pp. 40974-40980, ISSN 0021-9258

Ren, J., Singh, B.N., Huang Q., Li, Z., Gao, Y., Mishra, P. et al. (2011). DNA hypermethylation as a chemotherapy target. Cellular Signalling, Vol.23, No.27, (July 2011), pp. 1082-1093, ISSN 0898-6568

Renaud, S., Pugacheva, E.M., Delgado, M.D. et al. (2007). Expression of the CTCFparalogous cancer-testis gene, brother of the regulator of imprinted sites (BORIS), is regulated by three alternative promoters modulated by $\mathrm{CPG}$ methylation and by CTCF and p53 transcription factors. Nucleic Acids Research, Vol.35, No.21, pp. 73727388, ISSN 0305-1048

Riggs, A.D. (1975). X inactivation, differentiation, and DNA methylation. Cytogenetics and Cell Genetics, Vol.14, No.1, (January 1975), pp. 9-25, ISSN 0301-0171 
Risinger, J.I., Chandramouli, G.V., Maxwell, G.L. et al. (2007). Global expression analysis of cancer/testis genes in uterine cancers reveals a high incidence of BORIS expression. Clinical Cancer Research, Vol.13, No.6, (March 2007), pp. 1713-1719, ISSN 1078-0432

Robertson, J., Robertson, A.B. \& Klungland A. (2011). The presence of 5hydroxymethylcytosine at the gene promoter and not in the gene body negatively regulates gene expression. Biochemical and Biophysical Research Communications, Vol.411, No.1, (July 2011), pp. 40-43, ISSN 0006-291X

Rodríguez-Paredes, M. \& Esteller M. (2011). Cancer epigenetics reaches mainstream oncology. Nature Medicine, Vol.17, No.3. (March 2011), pp. 330-339, ISSN 1078-8956

Sakatani, T., Wei, M., Katoh, M. et al. (2001). Epigenetic heterogeneity at imprinted loci in normal populations. Biochemical and Biophysical Research Communications, Vol.283, No.5, (May 2001), pp. 1124-1130, ISSN 0006-291X

Santoro, R., D'Erme, M., Mastrantonio, S. et al. (1995). Binding of histone H1e-c variants to CpG-rich DNA correlates with the inhibitory effect on enzymic DNA methylation. The Biochemical Journal, Vol.305, No.3, (February 1995), pp. 739-744, ISSN 0264-6021

Santoro, R., D'Erme, M., Reale, A. et al. (1993). Effect of H1 histone isoforms on the methylation of single- and double-stranded DNA. Biochemical and Biophysical Research Communications, Vol.190, No.1, (January 1993), pp. 86-91, ISSN 0006-291X

Santourlidis, S., Florl, A., Ackermann, R. et al. (1999). High frequency of alterations in DNA methylation in adenocarcinoma of the prostate. Prostate, Vol.39, No.3, (May 1999), pp. 166-174, ISSN 0270-4137

Schaefer, M., Hagemann S., Hanna, K., Lyko, F. (2009). Azacytidine inhibits RNA methylation at DNMT2 target sites in human cancer cell lines. Cancer Research, Vol.69, No.20, (October 2009), pp.8127-8132, ISSN 0008-547

Sharif, J., Muto, M., Takebayashi, S. et al. (2007). The SRA protein Np95 mediates epigenetic inheritance by recruiting Dnmt1 to methylated DNA. Nature, Vol.450, No.7171, (December 2007), pp.908-912, ISSN 0028-0836

Sharma, R.A., Euden, S.A., Platton, S.L. et al. (2004). Phase I clinical trial of oral curcumin: biomarkers of systemic activity and compliance. Clinical Cancer Research, Vol.10, No.20, (October 2004), pp. 6847-6854, ISSN 1078-0432

Smith, I.M., Glazer, C.A., Mithani, S.K. et al. (2009). Coordinated activation of candidate proto-oncogenes and cancer testes antigens via promoter demethylation in head and neck cancer and lung cancer. PloS ONE 4(3): e4961. doi:10.1371/journal.pone.0004961, ISSN 1932-6203

Spaventi, R., Pečur, L., Pavelic, K., et al. (1994). Human tumour bank in Croatia: a possible model for a small bank as part of the future European tumour bank network. European Journal of Cancer, Vol.30A, No.3, (September 2008), p 419, ISSN 0959-8049

Stresemann, C., Bokelmann, I., Mahlknecht, U. et al. (2008). Azacytidine causes complex DNA methylation responses in myeloid leukemia. Molecular Cancer Therapeutics, Vol.7, No.9, (September 2008), pp. 2998-3005, ISSN 1535-7163

Stresemann, C. \&, Lyko, F. (2008). Modes of action of the DNA methyltransferase inhibitors azacytidine and decitabine. International Journal of Cancer, Vol.123, No.1, (July 2008), pp. 8-13, ISSN 0020-7136

Tahiliani, M., Koh, K.P., Shen, Y. et al. (2009). Conversion of 5-methylcytosine to 5hydroxymethylcytosine in mammalian DNA by MLL partner TET1. Science, Vol.324, No.5929, (May 2009), pp. 930-935, ISSN 0036-8075 
Takai, D., Gonzales, F.A., Tsai, Y.C. et al. (2001). Large scale mapping of methylcytosines in CTCF-binding sites in the human $\mathrm{H} 19$ promoter and aberrant hypomethylation in human bladder cancer. Human Molecular Genetics, Vol.10, No.23, (November 2001), pp. 2619-2626, ISSN 0964-6906

Takai, D. \& Jones, P.A. (2002). Comprehensive analysis of CpG islands in human chromosomes 21 and 22. Proceedings of the National Academy of Sciences of the United States of America, Vol.99, No.6, (March 2002), pp. 3740-3745, ISSN 0027-8424

Tremblay, K.D., Duran, K.L. \& Bartolomei, M.S. (1997). A 5' 2-kilobase-pair region of the imprinted mouse H19 gene exhibits exclusive paternal methylation throughout development. Molecular and Cellular Biology, Vol.17, No.8, (August 1997), pp. 43224329, ISSN 0270-7306

Ulaner, G.A., Vu, T.H., Li, T. et al. (2003a). Loss of imprinting of IGF2 and H19 in osteosarcoma is accompanied by reciprocal methylation changes of a CTCFbinding site. Human Molecular Genetics, Vol.12, No.5, (March 2003), pp. 535-549, ISSN 0964-6906

Ulaner, G.A., Yang, Y., Hu, J.F. et al. (2003b). CTCF binding at the insulin-like growth factorII (IGF2)/H19 imprinting control region is insufficient to regulate IGF2/H19 expression in human tissues. Endocrinology, Vol.144, No.10, (October 2003), pp. 4420-4426, ISSN 0013-7227

Ushijima, T., Watanabe, N., Shimizu, K. et al. (2005). Decreased fidelity in replicating CpG methylation patterns in cancer cells. Cancer Research, Vol.65, No.1, (January 2005), pp. 11-17, ISSN 0008-5472

Ushijima, T., Watanabe, N., Okochi, E. et al. (2003). Fidelity of the methylation pattern and its variation in the genome. Genome Research, Vol.13, No.5, (May 2003), pp. 868-874, ISSN 1088-9051

$\mathrm{Vu}$, T.H., Nguyen, A.H. \& Hoffman, A.R. (2010). Loss of IGF2 imprinting is associated with abrogation of long-range intrachromosomal interactions in human cancer cells. Human Molecular Genetics, Vol.19, No.5, (March 2010), pp. 901-919, ISSN 0964-6906

Wagner, J.R. \& Cadet, J. (2010). Oxidation reactions of cytosine DNA components by hydroxyl radical and one-electron oxidants in aerated aqueous solutions. Accounts of Chemical Research, Vol.43, No.4, (April 2010), pp. 564-571, ISSN 0001-4842

Wanunu, M., Cohen-Karni, D., Johnson, R.R. et al. (2011). Discrimination of methylcytosine from hydroxymethylcytosine in DNA molecules. Journal of the American Chemical Society, Vol.133, No.3, (January 2011), pp. 486-492, ISSN 0002-7863

Williams, K., Christensen, J., Pedersen, M.T. et al (2011). TET1 and hydroxymethylcytosine in transcription and DNA methylation fidelity. Nature, Vol.473, No.7347, (May 2011), pp. 343-348, ISSN 0028-0836

Witcher, M. \& Emerson, B.M. (2009). Epigenetic silencing of the p16INK4a tumor suppressor is associated with loss of CTCF binding and a chromatin boundary. Molecular Cell, Vol.34, No.3, (May 2009), pp. 271-284, ISSN 097-2765

Woloszynska-Read, A., James, S.R., Link, P.A. et al. (2007). DNA methylation-dependent regulation of BORIS/CTCFL expression in ovarian cancer. Cancer Immunity, Vol.7, (December 2007), p. 21, ISSN 1424-9634

Wyatt, G.R. \& Cohen, S.S. (1952). A new pyrimidine base from bacteriophage nucleic acids. Nature, Vol.170, No.4338, (December 1952), pp. 1072-1073, ISSN 0028-0836 
Yu, W., Ginjala, V., Pant, V. et al. (2004). Poly(ADP-ribosyl)ation regulates CTCF-dependent chromatin insulation. Nature Genetics, Vol.36, No.10, pp. 1105-1110. ISSN 1061-4036.

Zardo, G. \& Caiafa, P. (1998). The unmethylated state of CpG islands in mouse fibroblasts depends on the poly(ADP-ribosyl)ation process. The Journal of Biological Chemistry, Vol.273, No.26, (June 1998), pp. 16517-16520, ISSN 0021-9258

Zhang, H., Niu, B., Hu, J.F. et al. (2011). Interruption of intrachromosomal looping by CCCTC binding factor decoy proteins abrogates genomic imprinting of human insulin-like growth factor II. The Journal of Cell Biology, Vol.193, No.3, (May 2011), pp. 475-487, ISSN 0021-9525

Zhang, X., Gejman, R., Mahta, A. et al. (2010). Maternally expressed gene 3, an imprinted noncoding RNA gene, is associated with meningioma pathogenesis and progression. Cancer Research, Vol.70, No.6, pp. 2350-2358, (March 2010), ISSN 00085472 


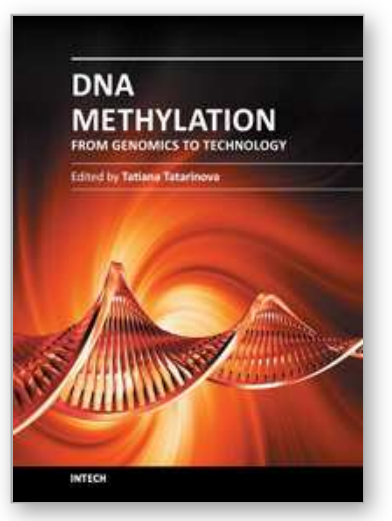

\author{
DNA Methylation - From Genomics to Technology \\ Edited by Dr. Tatiana Tatarinova
}

ISBN 978-953-51-0320-2

Hard cover, 400 pages

Publisher InTech

Published online 16, March, 2012

Published in print edition March, 2012

Epigenetics is one of the most exciting and rapidly developing areas of modern genetics with applications in many disciplines from medicine to agriculture. The most common form of epigenetic modification is DNA methylation, which plays a key role in fundamental developmental processes such as embryogenesis and also in the response of organisms to a wide range of environmental stimuli. Indeed, epigenetics is increasing regarded as one of the major mechanisms used by animals and plants to modulate their genome and its expression to adapt to a wide range of environmental factors. This book brings together a group of experts at the cutting edge of research into DNA methylation and highlights recent advances in methodology and knowledge of underlying mechanisms of this most important of genetic processes. The reader will gain an understanding of the impact, significance and recent advances within the field of epigenetics with a focus on DNA methylation.

\title{
How to reference
}

In order to correctly reference this scholarly work, feel free to copy and paste the following:

Koraljka Gall Trošelj, Renata Novak Kujundžić and Ivana Grbeša (2012). The Importance of Aberrant DNA Methylation in Cancer, DNA Methylation - From Genomics to Technology, Dr. Tatiana Tatarinova (Ed.), ISBN: 978-953-51-0320-2, InTech, Available from: http://www.intechopen.com/books/dna-methylation-fromgenomics-to-technology/the-importance-of-aberrant-dna-methylation-in-cancer

\section{INTECH}

open science | open minds

\author{
InTech Europe \\ University Campus STeP Ri \\ Slavka Krautzeka 83/A \\ 51000 Rijeka, Croatia \\ Phone: +385 (51) 770447 \\ Fax: +385 (51) 686166 \\ www.intechopen.com
}

\author{
InTech China \\ Unit 405, Office Block, Hotel Equatorial Shanghai \\ No.65, Yan An Road (West), Shanghai, 200040, China \\ 中国上海市延安西路65号上海国际贵都大饭店办公楼 405 单元 \\ Phone: +86-21-62489820 \\ Fax: $+86-21-62489821$
}


(C) 2012 The Author(s). Licensee IntechOpen. This is an open access article distributed under the terms of the Creative Commons Attribution 3.0 License, which permits unrestricted use, distribution, and reproduction in any medium, provided the original work is properly cited. 